\title{
Comparative Analysis on Contemporary Exam-oriented Education in Colleges and Universities in China and Western Liberal Educational Model
}

\author{
Kehui Zhang \\ School of Politics and Public Administration, Hainan University, Haikou Hainan, 570228, China
}

Key words: Exam-oriented education, Liberal education, Educational model, Comparative analysis.

\begin{abstract}
With the exploration of educational theory and practice and the communication with western educational theory circle, western liberal education has been introduced to theoretical research of Chinese colleges and universities. With the entry point of comparative analysis on differences of Chinese and western educational models in purpose, subjective relationship and effect of education and cultural atmosphere, this paper conducts theoretical exploration and research in order to promote the practice of reform of Chinese college education. The research shows that we should introduce liberal education, update educational concept, reform management style, develop subject consciousness and change campus atmosphere to establish the system of liberal education gradually in the practice of reform of exam-oriented educational model.
\end{abstract}

\section{Introduction}

As education has been regarded as a key factor for improving comprehensive national strength by various countries in the world in the internationalized modern society, they are endeavoring to create better education and changing the concept, system, content and mode of education. Therefore, we need to accept new idea, concept and information at the level of world historical course and advanced cultural development, absorb and learn from successful experience of various countries in the world in educational development and management, focus on improving the quality of college education, rethink and design educational management system and establish an educational system adapted to socialist market economy system and inherent law of education so as to show our unique strength and charm in the process of integrating with the world.

\section{Two different educational models}

\section{Contemporary "exam-oriented education" model in colleges and universities in China}

"Exam-oriented education" can be simply explained as education for examinations, which refers to a traditional educational model departing from actual demands of social development and human development, aiming at examinations and entry into a higher school and violating against scientific law of education. Such educational model emphasizes the impartment of conceptual knowledge to students by educators and the importance of score, generally makes knowledge exist out of actual demands and restricts the creativity of students to a great extent. Therefore, "exam-oriented education" is a negative concept denied by people in the field of Chinese and western education. It connects exam and education directly and regards test score as the final result of education.

Exam-oriented education is denounced widely. However, it is still pursued in Chinese colleges and universities due to the reason of history and the reality. On one hand, we believe that the vitality of exam-oriented education consists in its strong foundation, i.e. national psychology, national tradition, backward economic production mode, irrational urban-rural separation mechanism and limit of employment chance ${ }^{1}$.Traditional concepts emphasizing study and examination cause many college students in China to change their fate through study. The thought of entering into official career through fair examination has not quit the stage thoroughly with the change of the era.。 


\section{Western "liberal education" model}

Compared to exam-oriented educational model represented by China, liberal education is always the main educational concept of western colleges and universities in the whole history of western education. Its main principles are always pursued by people as a matter of course. The tradition of such educational thought is challenged in modern times with scientific progress, industrial development and social reform. According to the demonstration of ideologists of liberal education, "liberal education is cultural education or education aiming at cultural literacy. Its finished products are people with cultural accomplishment." Liberal education consists in the process of constant communication with the greatest thought. It is the most humble training. Liberal education aims at liberating people from philistinism, i.e. providing us with the experience of wonderful things. 。

\section{Analysis on differences of contemporary exam-oriented education in colleges and universities in China and western liberal education model}

\section{Social standard and individual standard: differences in educational purpose}

Educational purpose is the starting point and basis of educational activities as well as their result. Educational purpose is determined by the society, which reflects basic requirements of the society for the cultivation of people. Educational purposes of exam-oriented education and liberal education are different and even have essential differences.

From the perspective of its development process and social economic source, educational purpose of exam-oriented educational model reflects distinct features of social standard. According to social economic source of exam-oriented educational model, it is a solidified model of planned economy. Under planned economic system, there are relatively stable requirements for talents. Moreover, most educational resources are possessed by the government and allocated through instructions. Three basic problems of education solved by the government are what to learn, how to learn and why to learn. According to social economic source, liberal education develops with the development of free market and capitalist system.

\section{Initiative and passivity: differences in subjective relationship of education}

Teachers and students are basic subject of educational activities as well as the most direct manifestation of educational activities. Different educational models have different value basis, which influences the status of subjective relationship of education in the educational process. Under exam-oriented educational model, value orientation of educational purpose is based on the value of education adapted to the society. It neglects the value of education promoting individual development and fails to attach importance to the dominant position of human in education. It easily puts students in a passive non-subject position and causes the lack of subjectivity of human in the process of education. Main manifestations include the following: first, it emphasizes the link of teaching and pays attention to teachers rather than students; second, it emphasizes the method of management and pays attention to control rather than consciousness; third, it emphasizes the standard of cultivation and pays attention to uniformity rather than personality; forth, it emphasizes the effect of learning and pays attention to knowledge impartment rather than living practice and exploration. Thereby, teaching activities should establish the subjective role of students in study and regard students' demands as the starting point, thirst for knowledge and interests of students as inner motivation of teaching and the promotion of students' comprehensive development as the fundamental objective of teaching.

\section{Creating specific matters and cultivating people: difference in teaching effect}

Exam-oriented education and liberal education show their incompatibility and repellence in theory and practice. Their teaching effect also shows different results. First, training objectives deviate from correct objectives. Second, teaching method and measurement criteria neglect humanity. Colleges and universities advocate quality-oriented education and cultivate composite high-quality talents. 
The basic teaching method of exam-oriented education is cramming teaching method involving industrialized, flow line and standardized work. Its important standard for measuring and inspecting the learning attitude and effect of students is score. However, liberal education pays attention to lifetime success and happiness of students and promotes the achievement of students' short-term objective of entering a higher school on the basis of considering their long-term life objective. Examination is only a means. Its teaching skills consist in stimulating and developing students' potential. Main learning activities of students are to improve and develop their knowledge framework and practical ability based on their interests.

\section{Simplification and diversification: difference in campus culture}

Campus culture refers to spiritual wealth and cultural atmosphere created and formed by school teachers and students through education and educational activities and activity form and physical form carrying such spiritual wealth and cultural atmosphere. It includes physical culture, system culture and spiritual culture. Spiritual culture is the core of campus culture. As a power of environmental education, campus culture is influencing the healthy growth of college students subtly in various ways. Differences of exam-oriented education and free education are manifested in campus culture. Campus culture aiming at exam-oriented education has utilitarian objective, closed contents and one-sided evaluation etc. In terms of physical culture, it emphasizes achievement project and neglects the function of talent cultivation. Sometimes, it only considers first-class environment and equipment but fails to consider connotations and particularity of school. In terms of system culture, it is an "official" management concept and method, which is mechanical and stiff and lacks creativity. The thought of "being obedient to the authority" is serious. Children growing up under the environment of liberal education have distinct personality, independent thinking, sense of competition, open concept, scientific thought, creativity of seeking difference and new and free, equal and democratic political idea. The formation of such diversified cultural ecology lays a good foundation for comprehensive and healthy development of college students.

\section{Learning from and absorbing western liberal educational model in the reform of college education}

\section{Introduction of liberal education}

Rigid exam-oriented educational model can no longer meet talent demands under the market environment. Its quit will be the necessity of historical development. First, in terms of educational idea, it should regard education as both a means and an objective pursued by the subject rather than only regard education as a means for improving the quality of people. It is required to abandon the exam-centered educational development pattern and explore the integration of diversified teaching contents. Second, a stepped and planned transition should form. Universal application in educational reform should be avoided. Haste makes waste. It is necessary to promote the expansion and popularization of liberal educational model and form long-and-short combined periodic construction. Do not advance rashly for utility. Third, the practice and thought of wholesale westernization should be opposed in the process of establishing humanistic educational system. Educational model is closely related to social concept and mainstream ideology. The center of Chinese educational system is to serve people. While paying attention to develop the personality of learners and explore their learning potential, do not abandon this central link. Meanwhile, it is required to treat the experience of western liberal education scientifically, adhere to the principle of "selecting the essence and discarding the dross" and absorb it in dialectical way.

\section{Updating of educational concept}

The reform of college education starts from the updating of educational concept. To create better education and establish a power of higher education, the view of education based on the comprehensive development of human should be established first. The comprehensive development 
of human means that fundamental quality of human must be developed completely. It is concentrated reflection of Marxist theory about comprehensive development of human at educational level as well as fundamental aim of the reform of Chinese college education. Second, in terms of educational scale, education should face all people rather than a part of them and realize qualitative transition from quantitative accumulation. Due to the limit of productivity and economic level, the current education still stays among a part of people. Meanwhile, college expansion has caused excessive scale expansion and the reduction of school-running quality. Therefore, it is required to change the state as soon as possible, make everyone able to receive education, especially higher education, and improve the quality of talent training in colleges and universities. In addition, teaching reform should focus on cultivating the ability of students. Teaching method should change from classroom education to practical and social education. Teaching contents should change from the mastery of knowledge to the improvement of students' comprehensive ability. It is required to break the traditional exam-oriented educational model by changing classroom form, enriching teaching means, reducing the proportion of examination and improving evaluation system, make people actually become the target of education, respect the potential of each student, cultivate their ability of innovation and independent thinking, expand their horizon and allow them to achieve independent development.

\section{Cultivation of subject consciousness}

Developing and exerting the subject consciousness of college students is a historical tradition of world higher education as well as a distinct feature of modern education. To cultivate the subject consciousness of college students and make them become the subject of educational activities and self-development, the following aspects should be followed: first, an equal relationship between teachers and students must be established in teaching activities. It is required to overcome the deficiency of inequality of teacher-student relationship in the educational process due to the influence of authority view and cultivate students' spirit of independent thinking, doubt and criticism and their ambition of creation. Second, teachers should abandon obsolete teaching methods such as cramming and injection type education which constrain the initiative and creativity of students, fully arouse students' initiative, enthusiasm and innovation consciousness in study through teaching design, organization and management, make teaching process into a process of students' active and independent thinking and allow students to constantly improve their way of thinking, theoretical accomplishment, knowledge level and ability of analyzing and solving problems in the process.

\section{Reform of management style}

Contents of college management involve teaching, scientific research, teacher, student, administration and logistics etc. With different state system, ideology, times culture and management level, there will be different opinions on college management law and model. Most existing college management models in China belong to administrative model under which administrative function is implemented by means of executive power. It is used as the basis for management decision-making. Based on the significance of existence of colleges and universities and the starting point and foothold of management, modern colleges and universities should make a reform towards people-oriented management. As real colleges and universities are not commercial and political institutions, they are academic institutions. The mission, value and pursuit of scholars and universities belong to academy. Meanwhile, the starting point and foothold of management should be management efficiency. The improvement of management efficiency depends on the change of management thinking and the improvement of management level.

\section{Change of campus atmosphere}

Colleges are important achievement of cultural development as well as important carrier of cultural construction. As the base of talent training, they allow college students to have objective judgment or subjective perception for relevant interpersonal communication, academic communication and professional interactive environment on campus, which have great influence on the formation of their 
outlook on life and value, academic achievements and future development. Which campus atmosphere is beneficial to the development of contemporary college students? Tolerant, positive, healthy, fresh, elegant and harmonious campus atmosphere. Our body and soul will be damaged seriously. The influence of environmental quality on college students consists in it. First, it is required to pay attention to the cultivation of college humanistic spirit and attach great importance to mental strength of college development; second, build school buildings with good environment and complete facilities and create noble and healthy human landscape. Third, establish and improve internal management system of colleges and universities, establish harmonious interpersonal relationship on campus and form harmonious and positive educational environment; finally, cultivate advanced college culture and persist in guiding and shaping teachers, students and employees with cultural factors.

\section{Acknowledgement}

Topic level: provincial; topic name: Fund Project of Hainan Province for Improving Comprehensive Strength of Midwest Colleges and Universities; topic number: HNJY2014-1-2.

\section{References}

[1] Chen Xilin. Discussions on Root and Development Trend of Exam-oriented Education, New West, 2007(04):72-73.

[2] Gao Ying. Study on Western Critical Thinking: Retrospection and Introspection, Foreign Languages Research, 2014(5):1-6.

[3] Wang Jian. From "Campus Culture of Exam-oriented Education" to "Cultural Campus of Quality-oriented Education" - Discussions on Features and Transition of Current School Culture, Educational Theory and Practice, 2010(3):19-20. 